\title{
Genetic diversity and population structure of different varieties of Morada Nova hair sheep from Brazil
}

J.S.B. Ferreira ${ }^{1,5}$, S.R. Paiva ${ }^{2,6}$, E.C. Silva ${ }^{3}$, C.M. McManus ${ }^{4}$, A.R. Caetano ${ }^{2,3}$, D.A.E. Façanha ${ }^{1,5}$ and M.A.N. de Sousa ${ }^{1,5}$

${ }^{1}$ Programa de Pós-Graduação em Produção Animal, Universidade Federal Rural do Semi-Árido, Mossoró, RN, Brasil ${ }^{2}$ Embrapa Recursos Genéticos e Biotecnologia, Brasília, DF, Brasil ${ }^{3}$ Programa de Pós-Graduação em Ciências Animais, Universidade de Brasília, Brasília, DF, Brasil

${ }^{4}$ Departamento de Zootecnia, Universidade Federal do Rio Grande do Sul, Porto Alegre, RS, Brasil

${ }_{5}^{5}$ Departamento de Ciências Animais, Universidade Federal Rural do Semi-Árido, Mossoró, RN, Brasil ${ }^{6}$ Embrapa Sede, Secretaria de Relações Internacionais, Programa Labex EUA, Brasília, DF, Brasil

Corresponding author: S.R. Paiva

E-mail: samuel.paiva@embrapa.br

Genet. Mol. Res. 13 (2): 2480-2490 (2014)

Received January 8, 2013

Accepted June 17, 2013

Published April 3, 2014

DOI http://dx.doi.org/10.4238/2014.April.3.20

\begin{abstract}
The aim of this study was to analyze genetic diversity and population structure among varieties of White $(\mathrm{N}=40)$, $\operatorname{Red}(\mathrm{N}=32)$, and Black $(\mathrm{N}=31)$ Morada Nova hair sheep from flocks in the northeastern Brazilian semiarid region. Fifteen nuclear microsatellite markers and two regions of mitochondrial DNA were used. The intra-population analysis demonstrated that the White variety had higher diversity, while the Red variety had the lowest values. The Bayesian analysis to assess the genetic population structure allowed differentiation between White, Red, and
\end{abstract}


Black varieties, and revealed a tendency towards sub-structuring in the White variety flocks from the States of Ceará and Paraíba. The results of analyses of molecular variance showed that the greatest genetic structure was found when comparing flocks rather than varieties (8.59 vs $6.64 \%$ of the total variation, $\mathrm{P}<0.001)$. Based on genetic distance, Dtl, both the dendrogram analysis and the principal coordinate analysis showed the formation of two main groups: one composed of White and another of Black and Red individuals. Five and two haplotypes were found for the D-loop region and the ND5 gene, respectively. A haplotype unique to the Red variety was found in the D-loop region and a variety haplotype unique to the Black variety was found in the ND5 gene; however, these frequencies were low and therefore require further validation. These results support the existence of substantial differences between the Red and White varieties and should be used as separate genetic resources and to improve conservation programs.

Key words: Ovis aries; mtDNA; Animal genetic resources; Microsatellites; Genetic management

\section{INTRODUCTION}

Brazil has several breeds of domestic animals that developed from those originally introduced by Portuguese colonists. These populations were selected naturally by local climatic conditions, giving rise to Brazilian breeds, also known as local or creole breeds (Mariante et al., 2009). The industrial culture created during the twentieth century has led to changes in production systems and breeds used in local production systems (McManus et al., 2011). Breeds considered exotic, highly productive, but selected mostly in temperate regions were imported and used in crossbreeding, causing rapid replacement and genetic erosion of local breeds (Egito et al., 2002).

The Brazilian association of sheep farmers (ARCO) recognizes the existence of two varieties of the Morada Nova hair sheep breed: Red and White coated. Black-coated Morada Nova can also be observed in production flocks, although it is currently not recognized by the Genealogical Registry Service of Sheep Breeds (SRGRO). A study carried out by Paiva (2005) using the D-loop region and 19 microsatellite markers revealed that the Red and White Morada Nova sheep varieties have different genetic variations, and could therefore be considered as distinct genetic groups. However, this study included only a single flock of each variety, White and Red, and did not include the Black type. Thus, the present study aimed to validate this differentiation in other flocks and to test whether the black-coated animals might be considered genetically distinct by using nuclear microsatellite and mitochondrial DNA (mtDNA) markers.

\section{MATERIAL AND METHODS}

Blood samples were collected from 103 Morada Nova sheep with Red, White, and Black coat colors (Table 1). DNA was extracted from lymphocytes using standard procedures (Miller et al., 1988) and was quantitated by spectrophotometry (Nanodrop ND1000 ${ }^{\circledR}$ ). 


\begin{tabular}{|c|c|c|c|c|c|c|}
\hline Farm & Geographic position & State & OMN_R & OMN_W & OMN_B & $\overline{\mathrm{T}}$ \\
\hline$\overline{\mathrm{A}}$ & $\begin{array}{l}5^{\circ} 6^{\prime} 20^{\prime \prime S} \\
38^{\circ} 22^{\prime 2} 2^{\prime \prime} \mathrm{W}\end{array}$ & $\mathrm{CE}$ & 4 & - & - & $\overline{4}$ \\
\hline B & $\begin{array}{l}5^{\circ} 6^{\prime} 20^{\prime \prime S} \\
38^{\circ} 22^{\prime 2} 2^{\prime \prime} \mathrm{W}\end{array}$ & $\mathrm{CE}$ & 4 & - & 2 & 6 \\
\hline $\mathrm{C}$ & $\begin{array}{l}5^{\circ} 6^{\prime} 20 " \mathrm{~S} \\
38^{\circ} 22^{2} 2^{\prime \prime} \mathrm{W}\end{array}$ & $\mathrm{CE}$ & 4 & - & - & 4 \\
\hline $\mathrm{D}^{*}$ & $\begin{array}{l}4^{\circ} 58^{\prime} 41 " \mathrm{~S} \\
39^{\circ} 1^{\prime} 8^{\prime \prime} \mathrm{W}\end{array}$ & $\mathrm{CE}$ & - & 13 & - & 13 \\
\hline $\mathrm{E}^{*}$ & $\begin{array}{l}3^{\circ} 47^{\prime} 29^{\prime \prime} \mathrm{S} \\
39^{\circ} 15^{\prime} 58^{\prime \prime} \mathrm{W}\end{array}$ & $\mathrm{CE}$ & - & 8 & - & 8 \\
\hline $\mathrm{F}$ & $\begin{array}{l}7^{\circ} 17^{\prime} 53^{\prime \prime S} \\
35^{\circ} 28^{\prime} 41^{\prime \prime} \mathrm{W}\end{array}$ & $\mathrm{PB}$ & 20 & 19 & 8 & 47 \\
\hline $\mathrm{G}$ & $\begin{array}{l}5^{\circ} 40^{\prime} 18^{\prime \prime S} \\
36^{\circ} 36^{\prime} 17^{\prime \prime} \mathrm{W}\end{array}$ & $\mathrm{RN}$ & - & - & 14 & 14 \\
\hline $\mathrm{H}$ & $\begin{array}{l}5^{\circ} 34^{\prime} 38^{\prime \prime} \mathrm{S} \\
36^{\circ} 54^{\prime} 30^{\prime \prime} \mathrm{W}\end{array}$ & RN & - & - & 7 & 7 \\
\hline Total & & & 32 & 40 & 31 & 103 \\
\hline
\end{tabular}

OMN R = Red variety; $\mathrm{OMN} W \mathrm{~W}=$ White variety; and $\mathrm{OMN} \mathrm{B}=$ Black variety; $\mathrm{T}=$ total number of animals collected. *Experimental farm representative of conservation nucleus. $\overline{\mathrm{CE}}=$ Ceará; $\mathrm{PB}=$ Paraíba; $\mathrm{RN}=$ Rio Grande do Norte.

A total of 15 microsatellite markers was used to characterize each sample. Polymerase chain reaction (PCR) was performed in multiplex or single-locus reactions (Supplementary material A). PCR was performed with the Qiagen Master Mix Kit ${ }^{\circledR}$, according to manufacturer recommendations, as follows: $2.5 \mu \mathrm{LPCR}$ mix, $0.5 \mu \mathrm{LQ}$ solution, $0.2 \mu \mathrm{M}$ of each primer, and $0.9 \mathrm{ng}$ DNA, in a final volume of $5 \mu \mathrm{L}$. Amplifications were performed in Veriti ${ }^{\circledR}$ Model 96-well Thermal Cyclers (Applied Biosystems) as follows: 1 cycle of $95^{\circ} \mathrm{C}$ for $15 \mathrm{~min}, 36$ cycles of $94^{\circ} \mathrm{C}$ for $30 \mathrm{~s}$, annealing at $57^{\circ} \mathrm{C}$ for $30 \mathrm{~s}$, and extension at $72^{\circ} \mathrm{C}$ for $1 \mathrm{~min}$, followed by a final step of $72^{\circ} \mathrm{C}$ for $30 \mathrm{~min}$. PCR products were electrophoresed in an ABI PRISM $3100^{\circledR}$ instrument, and data were analyzed using the GeneScan software v.3.1.v and Genotyper 3.7.0.1 (Applied Biosystems). Identification of allelic classes was performed with the FlexiBin v.2.0 software (Amos et al., 2007).

GenAlex v.6.4 (Peakall and Smouse, 2006) and Molkin 3.0 (Gutiérrez et al., 2005) were used to estimate the effective number of alleles $\left(N_{\mathrm{E}}\right)$, the mean number of alleles $\left(N_{\mathrm{M}}\right)$, the expected heterozygosity $\left(H_{\mathrm{E}}\right)$, the observed heterozygosity $\left(H_{\mathrm{O}}\right)$, and the polymorphic information content (PIC). Wright's F statistics $\left(F_{\mathrm{IS}}, F_{\mathrm{IT}}\right.$, and $\left.F_{\mathrm{ST}}\right)$ were also calculated (Weir and Cockerham, 1984) using FSTAT v.2.9.3.2 (Goudet, 2002). Hardy-Weinberg equilibrium (HWE) tests within populations and loci were performed with Genepop v.4.0.10 (Raymond and Rousset, 1995).

For the principal coordinate analysis (PCoA), genetic distance (Dtl; Tomiuk et al., 1998) was calculated based on genotypic frequencies with Molkin v.3.0 (Gutiérrez et al., 2005) between each pair of individuals. This distance was inserted into GenAlex (Peakall and Smouse, 2006), substituting the previously calculated genetic distance, to carry out the PCoA. The matrix obtained from the distance Dtl was used in the SplitsTree software 4.12.3 (Huson and Bryant, 2006) for construction of the dendrogram by the unweighted pair group method with arithmetic mean (UPGMA).

Structure v.2.3.4 (Pritchard et al., 2000) was used to estimate the most likely number of populations in which the genotypes studied could be distributed. Probabilities for the number of populations $(\mathrm{K})$, ranging from 1 to 18, were estimated. Each $\mathrm{K}$ was tested in five replicates consisting of 100,000 burn-in iterations and 400,000 iterations of Markov Chains and Monte Carlo simulations (MCMC). Data from MAF214, OLADRB, OarAE129, and MAF214 were excluded 
from the analysis as they were not in HWE in one or more of the tested breed types.

Analysis of molecular variance (AMOVA) was performed in Arlequin v.3.1 (Excoffier et al., 2006). Three different contrasts were performed to test the effects of flock ( $\mathrm{N}=8)$, state of origin $(\mathrm{N}=3)$, and breed type $(\mathrm{N}=3)$.

mtDNA fragments from ND5 (Tserenbataa et al., 2004) and the D-loop (Meadows et al, 2005) were amplified with previously published primers and conditions: ND5L (5'-AATAGT TTATCCAGTTGGTCTTAGG-3'), ND5RI (5'-AAGATTTGTTGGAGATCTCAGGTG-3'); and MTCR-F2 (5'-AACTGCTTGACCGTACATAGTA-3'), MTCR-R1 (5'-AGAAGGGTATA AAGCACCGCC-3'), respectively. Purified PCR fragments were sequenced with an ABI PRISM $3730^{\circledR}$ instrument, with BigDye v3.0 chemistry.

Mitochondrial marker sequences were analyzed and edited with the aid of SeqScape ${ }^{\circledR}$ version 2.7 (Applied Biosystems) using AF010406 as the reference sequence (Hiendleder et al., 1998). After editing, MEGA version 5.5 (Tamura et al., 2011) was used for aligning the sequences with sequences obtained from GenBank (Supplementary material B) and also for production of the input files for calculating the diversity of the sequences. DNAsp v.5 (Librado and Rozas, 2009) was used to estimate the number of polymorphic sites, haplotype number, haplotype diversity, and nucleotide diversity. The relationship between the number of haplotypes generated and found was analyzed by constructing a haplotypic network using the Network version 4.1.1.2 program (Fluxus Technology Ltd. - www.fluxus-engineering.com) using median-joining (Bandelt et al., 1999).

\section{RESULTS}

All loci tested were polymorphic (Table 2). The number of observed alleles per locus ranged from 2 to 8, and $N_{\mathrm{M}}$ ranged from 2 (MAF214) to 6.667 (OLADRB and OarHH35), with an average of 4.622. The average PIC observed was 58.64\% and MAF214 (36.41\%) and OLADRB (78.21\%) had the lowest and highest values, respectively.

\begin{tabular}{|c|c|c|c|c|c|c|c|c|c|c|}
\hline Loci & $N_{\mathrm{T}}$ & $N_{\mathrm{M}}$ & $N_{\mathrm{E}}$ & $H_{\mathrm{O}}$ & $H_{\mathrm{E}}$ & PIC (\%) & $F_{\text {IT }}$ & $F_{\mathrm{ST}}$ & $F_{\text {IS }}$ & HWE \\
\hline D5S2 & 3 & 2.333 & 1.955 & 0.43 & 0.483 & 40.46 & 0.130 & -0.004 & 0.131 & 1 \\
\hline$O L A D R B$ & 8 & 6.667 & 4.282 & 0.688 & 0.752 & 78.21 & 0.175 & 0.073 & $0.154 * *$ & 3 \\
\hline OarAE129 & 4 & 4 & 2.116 & 0.263 & 0.498 & 52.73 & 0.602 & 0.245 & $0.567 * *$ & 3 \\
\hline OarFCB304 & 7 & 5.333 & 3.297 & 0.686 & 0.691 & 66.66 & 0.043 & 0.000 & 0.043 & - \\
\hline SPS113 & 7 & 6.333 & 3.662 & 0.663 & 0.723 & 72.08 & 0.140 & 0.044 & $0.127 * *$ & - \\
\hline INRA05 & 6 & 4.667 & 1.926 & 0.381 & 0.411 & 45.57 & 0.225 & 0.158 & $0.182 * *$ & - \\
\hline INRABERN172 & 6 & 5 & 1.827 & 0.394 & 0.427 & 40.48 & 0.118 & 0.021 & 0.112 & 1 \\
\hline MAF65 & 5 & 4.333 & 3.575 & 0.703 & 0.698 & 70.67 & 0.088 & 0.067 & 0.068 & 1 \\
\hline INRA35 & 5 & 5 & 2.617 & 0.646 & 0.618 & 60.46 & 0.000 & 0.031 & -0.01 & - \\
\hline ILSTSII & 4 & 4 & 2.577 & 0.52 & 0.588 & 58.58 & 0.206 & 0.073 & $0.186^{* *}$ & 1 \\
\hline$M A F 214$ & 2 & 2 & 1.823 & 0.266 & 0.446 & 36.41 & 0.443 & 0.104 & $0.423 * *$ & 2 \\
\hline INRA63 & 7 & 4.667 & 3.048 & 0.616 & 0.659 & 63.04 & 0.116 & 0.035 & $0.105^{*}$ & - \\
\hline OarHH35 & 7 & 6.667 & 3.395 & 0.74 & 0.702 & 74.22 & 0.095 & 0.123 & 0.057 & - \\
\hline SRCRSP5 & 3 & 3 & 2.164 & 0.351 & 0.521 & 48.44 & 0.375 & 0.027 & $0.369 * *$ & 2 \\
\hline МСM527 & 7 & 5.333 & 3.65 & 0.646 & 0.722 & 71.54 & 0.153 & 0.039 & $0.142 * *$ & 1 \\
\hline Total & 5.4 & 4.622 & 2.794 & 0.533 & 0.596 & 58.64 & 0.185 & 0.070 & $0.166^{* *}$ & \\
\hline
\end{tabular}

$N_{\mathrm{T}}=$ total number of alleles; $N_{\mathrm{M}}=$ average number of alleles; $N_{\mathrm{E}}=$ effective number of alleles; $H_{\mathrm{O}}=$ observed heterozygosity; $H_{\mathrm{E}}=$ expected heterozygosity; $\mathrm{PIC}=$ polymorphic information content; $F_{\mathrm{IS}}=$ fixation index within populations; $F_{\mathrm{IT}}=$ fixationon index of the global population; $F_{\mathrm{ST}}=$ coefficient of relatedness between individuals from different populations; HWE = number of studied varieties that deviated from Hardy-Weinberg equilibrium $(\mathrm{P}$ $<0.05) ; * \mathrm{P}<0.05 ; * * \mathrm{P}<0.01$. 
Of the 15 loci analyzed, 12 presented $H_{\mathrm{O}}$ values that were smaller than the $H_{\mathrm{E}}$ values. The lowest $H_{\mathrm{O}}$ was 0.263 for OarAE129 and the highest was 0.740 for OarHH35, with an average of 0.533 . The White variety had the highest calculated genetic diversity indices, followed by Black (Table 3). The imbalance between $H_{\mathrm{O}}$ and $H_{\mathrm{E}}$ was caused by a significant deficiency of heterozygotes at each locus, as confirmed by the significance test for $F_{\text {IS }}$ (Supplementary material C). Mean values for $F_{\mathrm{IT}}, F_{\mathrm{ST}}$, and $F_{\mathrm{IS}}$ were $18.5,7.0$, and $12.4 \%$, respectively.

Table 3. Estimate of genetic diversity of the varieties of Morada Nova sheep through the 15 microsatellite loci.

\begin{tabular}{llllllc}
\hline Variety & $\mathrm{N}$ & $N_{\mathrm{M}}$ & $N_{\mathrm{E}}$ & $H_{\mathrm{O}}$ & $H_{\mathrm{E}}$ & PIC (\%) \\
\hline OMN_R & 32 & 4.467 & 2.637 & 0.5 & 0.588 & 40.55 \\
OMN_W & 40 & 4.8 & 2.995 & 0.568 & 0.617 & 46.13 \\
OMN_B & 31 & 4.6 & 2.751 & 0.53 & 0.583 & 40.34 \\
Mean & & 4.622 & 2.794 & 0.533 & 0.596 & 42.34 \\
\hline
\end{tabular}

$\mathrm{N}=$ number of samples used in the analysis; $N_{\mathrm{M}}=$ average number of alleles; $N_{\mathrm{E}}=$ effective number of alleles; $H_{\mathrm{O}}=$ observed heterozygosity; $H_{\mathrm{E}}=$ expected heterozygosity; $\mathrm{PIC}=$ polymorphic information content; $\mathrm{HWE}=$ number of loci that deviated from the Hardy-Weinberg equilibrium $(\mathrm{P}<0.05)$; OMN_R $=$ Red variety; OMN_W $=$ White variety, and OMN_B = Black variety.

For the inter-population analysis, the first of three components (Figure 1) from the PCoA explained $62.67 \%$ of the observed variation among the Morada Nova varieties. The first, second, and third components explained $27.93,18.86$, and $15.88 \%$ of the total variation, respectively. There were two well-defined groups, one corresponding to the White variety and the other corresponding to the Red variety. Individuals representing the Black variety were dispersed among individuals of the two former groups.
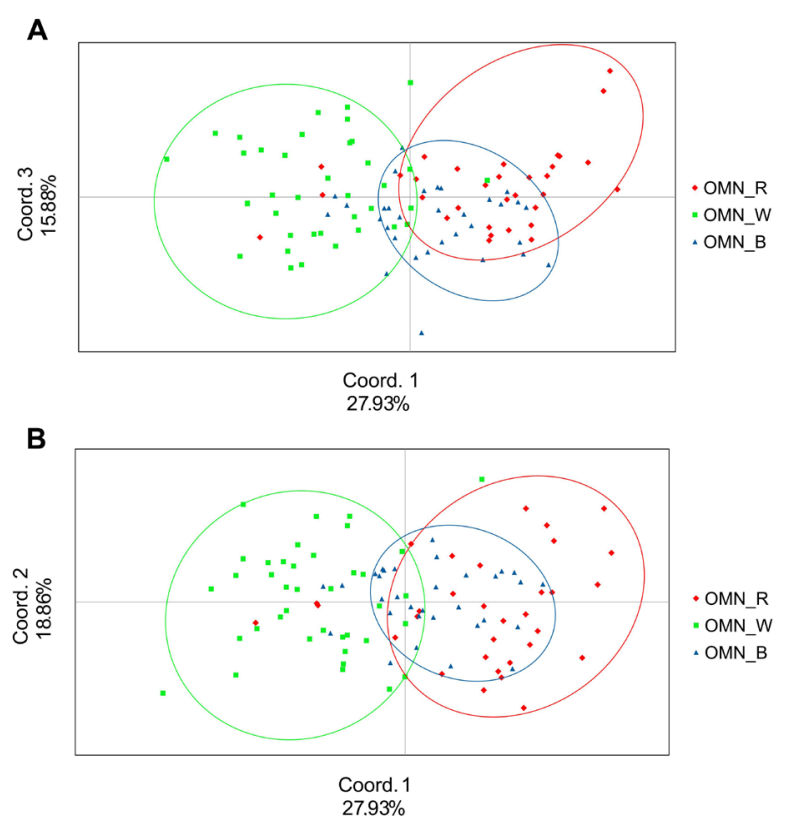

Figure 1. Dimensional representation of principal coordinate analysis of three varieties of the Morada Nova sheep breed. OMN_R $=$ Red variety, OMN_W $=$ White variety, and OMN_B $=$ Black variety. A. First and third principal coordinates. B. First and second principal coordinates. 
A dendrogram containing all analyzed individuals (Supplementary material D) was constructed based on the UPGMA method using the estimated distance Dtl. Two main groups were formed, one comprised mostly of White individuals and another was formed by individuals of the Red and Black varieties, with some exceptions, corroborating the results obtained in the PCoA. AMOVA results (Table 4) revealed significant $(\mathrm{P}<0.001) F_{\mathrm{ST}}$ values when the data were grouped by flock $(8.59 \%)$, state $(3.19 \%)$, and variety $(6.64 \%)$. Structure analyses showed the existence of four populations $(\mathrm{K})$ in the analyzed samples (Supplementary material E). When using $\mathrm{K}=2$, a group formed by the White variety and another for the Red and Black varieties were revealed (Figure 2). The Red, White, and Black varieties of Morada Nova were grouped into different clusters when $\mathrm{K}=3$ was used, showing that only a small proportion of individuals of each variety is mixed, since the three varieties share alleles. Sub-structuring within the White variety, representing animals from the states of Ceará and Paraíba, was observed with $\mathrm{K}=4$ (Supplementary material F).

Table 4. Analysis of molecular variance (AMOVA) at different levels of structure for three varities of Morada Nova hair sheep.

\begin{tabular}{|c|c|c|c|c|c|c|}
\hline Structure & Source of variation & d.f. & SS & $\mathrm{CV}$ & $\%$ Variation & $F_{\mathrm{ST}}$ \\
\hline \multirow[t]{3}{*}{ I } & Between flocks & 7 & 83.289 & 0.36685 & 8.59 & $0.08586^{*}$ \\
\hline & Within flocks & 198 & 773.391 & 3.90601 & 91.41 & \\
\hline & Total & 205 & 856.680 & 4.27287 & & \\
\hline \multirow[t]{3}{*}{ II } & Between states & 2 & 25.798 & 0.13469 & 3.19 & $0.03186^{*}$ \\
\hline & Within states & 203 & 830.882 & 4.09301 & 96.81 & \\
\hline & Total & 205 & 856.680 & 4.22771 & & \\
\hline \multirow[t]{3}{*}{ III } & Between varieties & 2 & 46.671 & 0.28368 & 6.64 & $0.06638 *$ \\
\hline & Within varieties & 203 & 810.008 & 3.99019 & 93.36 & \\
\hline & Total & 205 & 856.680 & 4.27387 & & \\
\hline
\end{tabular}

d.f. $=$ degrees of freedom; $\mathrm{SS}=$ sum of squares; $\mathrm{CV}=$ coefficient of variation; $F_{\mathrm{ST}}=$ fixation index. $* \mathrm{P}<0.001$.

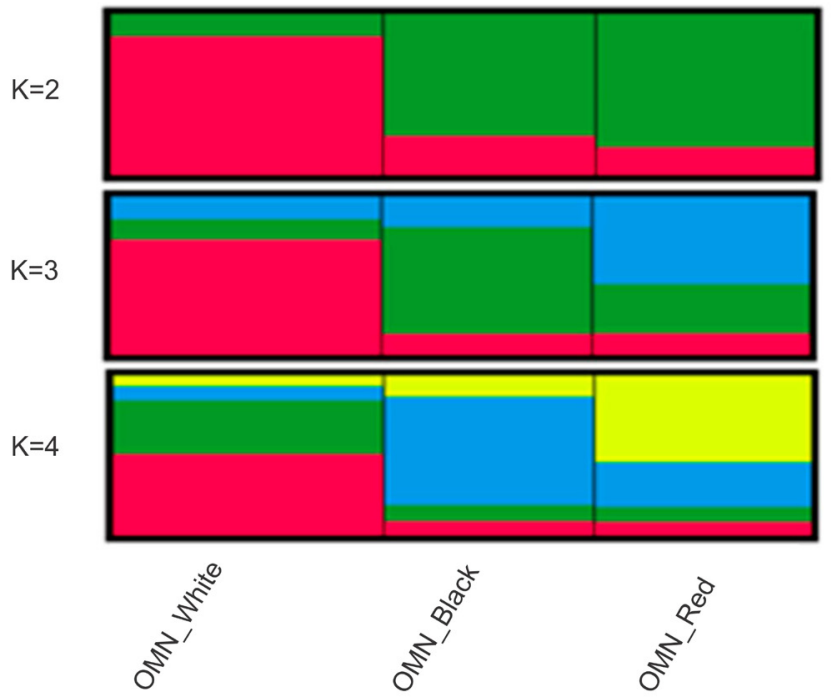

Figure 2. Distribution of proportions of each individual in each cluster inferred by Structure with $\mathrm{K}=2,3,4$. Black vertical lines separate the varieties. OMN_R $=$ Red variety, OMN_W $=$ White variety, and OMN_B $=$ Black variety. 
A total of five haplotypes, composed of eight single nucleotide polymorphisms (SNPs), were identified within the analyzed 524-bp D-loop fragment when sequences were compared with the ovine reference mtDNA (GenBank AF010406) sequence (Supplementary material G). The most frequent haplotype was $\mathrm{H} 2$, whereas $\mathrm{H} 2$ and $\mathrm{H} 4$ were found to be unique to the Morada Nova breed (Table 5). Haplotype diversity $\left(H_{\mathrm{d}}\right)$ and nucleotide diversity $(\pi)$ were estimated to be $0.721( \pm 0.025)$ and $0.00349( \pm 0.00012)$, respectively. Among the varieties studied, $H_{\mathrm{d}}$ and $\pi$ varied from $0.782( \pm 0.042$; Red breed) to $0.66( \pm 0.057$; Black $)$ and from $0.00436( \pm 0.00028$; Black) to 0.00395 ( \pm 0.00017 ; White) (Table 6). In order to compare these haplotypes with the ones published by Paiva et al. (2011), a 460-bp fragment of D-loop region was analyzed in conjunction with the Brazilian Somali hair sheep breed sequences available in GenBank (Figure 3). Three haplotypes identified in Morada Nova (H4, H10 and H12) corresponded with haplotypes H3, H9, and H11 identified by Paiva et al. (2011), respectively. When we compared these haplotypes with Table 5, the $\mathrm{H} 4$ (Figure 3) is the merging of $\mathrm{H} 2$ and $\mathrm{H} 4$ (Table 5), $\mathrm{H} 10$ is the merging of $\mathrm{H} 1$ and $\mathrm{H} 5$, and $\mathrm{H} 12$ corresponds to $\mathrm{H} 3$.

Table 5. Haplotype frequencies of the D-loop and ND5 mtDNA regions within the three varieties of Morada
Nova sheep studied.
\begin{tabular}{lccccccc} 
Variety & \multicolumn{7}{c}{ D-loop } \\
\cline { 2 - 8 } & $\mathrm{H} 1$ & $\mathrm{H} 2$ & $\mathrm{H} 3$ & $\mathrm{H} 4$ & $\mathrm{H} 5$ & $\mathrm{H} 1$ & $\mathrm{H} 5$ \\
\hline Red & 0.054 & 0.098 & 0.022 & 0.076 & 0.033 & 0.337 & - \\
White & 0.174 & 0.141 & 0.011 & 0.065 & - & 0.373 & - \\
Black & 0.087 & 0.163 & 0.065 & 0.011 & - & 0.277 & 0.012 \\
Total & 0.315 & 0.402 & 0.098 & 0.152 & 0.033 & 0.987 & 0.012 \\
\hline
\end{tabular}

Table 6. Variability parameters for the D-loop region and the mtDNA ND5 gene within the varieties of Morada
Nova sheep.
\begin{tabular}{lccccccc}
\hline Parameters & D-loop & \multicolumn{3}{c}{ ND5 } \\
\cline { 2 - 4 } \cline { 5 - 7 } & OMN_R & OMN_W & OMN_B & & OMN_R & OMN_W & OMN_B \\
\hline No. of individuals & 26 & 36 & 30 & & 28 & 31 & 24 \\
No. of haplotypes & 5 & 5 & 5 & & 1 & 1 & 2 \\
No. of polymorphic sites & 6 & 5 & 5 & & 0 & 1 \\
Haplotype diversity $\left(H_{\mathrm{d}}\right)$ & $0.782(0.042)$ & $0.662(0.041)$ & $0.660(0.057)$ & & 0 & $0.083(0.075)$ \\
Nucleotide diversity $(\pi)$ & $0.00432(0.00044)$ & $0.00395(0.00017)$ & $0.00436(0.00028)$ & 0 & 0 & $0.00019(0.00017)$ \\
\hline
\end{tabular}

OMN_R = Red variety; OMN_W $=$ White variety; OMN_B $=$ Black variety.

For the fragment corresponding to the ND5 region, $435 \mathrm{bp}$ were obtained after editing, and the region was located between positions 11846 and 12281 of the complete mtDNA sequence of $O$. aries (GenBank: AF010406) (Hiendleder et al., 1998). Only two haplotypes were identified, which differed by only a SNP (transition T/C at position 11883). Most of the sequences in that region were grouped in the same $\mathrm{H} 1$ haplotype as the $O$. aries sequence (AF010406). Only one individual of the Black variety from farm G-RN was clustered in the H2 haplotype (Supplementary material $\mathbf{H}) . H_{\mathrm{d}}$ and $\pi$ for the ND5 region were, respectively, $0.024( \pm 0.023)$ and $0.00006( \pm 0.00005)$. For the Red and White varieties, values of $H_{\mathrm{d}}$ and $\pi$ were equal to zero, and for Black were $0.083( \pm 0.075)$ and $0.00019( \pm 0.00017)$, respectively (Table 6). 


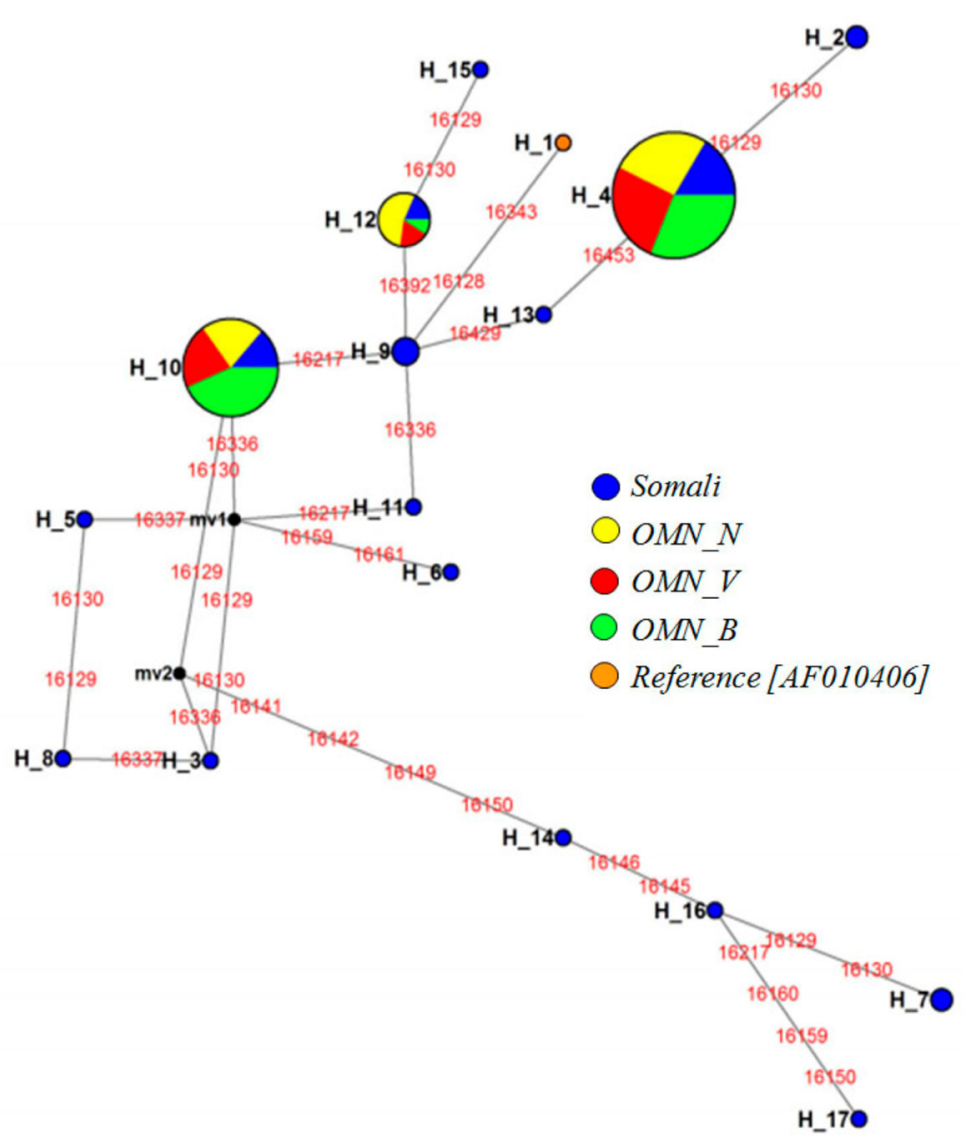

Figure 3. Median-joining network generated from $460 \mathrm{bp}$ in the control region (D-loop) of mitochondrial DNA using the Network program. The sizes of the circles of haplotypes are proportional to their frequencies, and numbers in red indicate the position of the mutations that differentiate each haplotype. OMN_R $=$ Red variety, OMN_W = White variety, and OMN_B = Black variety.

\section{DISCUSSION}

Efforts to conserve rare breeds and to maintain maximum genetic variability of their varieties is of great strategic importance to ensure the long-term sustainability of animal production activities in both subsistence and commercial farms, especially when considering major global climate change forecasts (McManus et al., 2011; Fiore et al., 2012). Genetic studies with molecular tools from different locally adapted sheep breeds from different regions of the world have been used as guidance for decision making in conservation programs, training, as well as inclusion and/or exclusion of genetic groups in gene banks (Dalvit et el., 2009; Paiva et al., 2011; Qwabe et al., 2013). Different classes of molecular markers have been used across studies related to the conservation and improvement of genetic resources (Cinkulov et al., 2008; Pariset et al., 2011). Each marker conveys a different type of genetic information. According to Paiva et al. (2011), the use of only one class of marker (typically microsatellites) 
to inform maintenance and management policies is not desirable because one marker cannot provide all of the necessary genetic information. Studies involving Morada Nova sheep have been developed using RAPD (Paiva et al., 2005a), PCR-RFLP (Paiva et al., 2005b), microsatellites, and mtDNA (Paiva, 2005; McManus et al., 2010) markers. Paiva (2005) analyzed microsatellite genetic divergence between two herds of White and Red varieties and identified significant differences between them. This result was expanded and confirmed in the present study, thereby justifying the creation and maintenance of germplasm banks for both varieties.

The occurrence of two groups within the White variety, from the States of Ceará and Paraíba (Figure 2, $\mathrm{K}=4$ ), draws attention to possible inclusion of animals from farm $\mathrm{F}$ (Paraíba State) in conservation nuclei (in situ conservation program), since the individuals from farms D and E from Ceará originated from existing conservation nuclei for the breed. With respect to the Black variety, the structure results, principal coordinates, and phylogenetic tree by the UPGMA analyses all validated the hypothesis that this is a subgroup of the Red variety. Nonetheless, this subgroup presents unique genetic combinations in microsatellite markers. Therefore, further studies are needed with these animals, since there is strong selection against this phenotype, as they are not recognized by the Breeder's Association and Brazilian Ministry of Agriculture, Livestock and Supplies.

Among farmers, the black color in Morada Nova is recognized as a recessive trait, since despite intense selection against it, the color reappears in the population as a result of matings between individuals of the Red variety. Variation in coat coloration is due to the presence, distribution, and activity of melanocytes that produce two kinds of pigments, eumelanin, and pheomelanin, leading to the colors black/tan and red/yellow, respectively (Searle, 1968). The production of these pigments is controlled by the extension (E) locus, which corresponds to the MCIR gene, and agouti (A), which corresponds to the ASIP gene. In some mammals, the extension locus shows an epistatic effect on the agouti locus. Dominant alleles at this locus are responsible for the black coat phenotype. Norris and Whan (2008) noted that a tandem duplication of a 190-kb sequence, including coding regions of the ASIP gene of sheep, the $\mathrm{AHCY}$ coding region, and the ITCH promoter region, is the cause of the dominant white color of sheep. Mutations in another gene (TYRP1) have also been associated with color variation in a number of mammals, including domestic cattle (Berryere et al., 2003) and sheep (Gratten et al., 2007). Therefore, studies on Morada Nova sheep, including individuals with black hair, can contribute to the worldwide effort to elucidate the inheritance of coat color in sheep.

Two specific haplotypes of the two D-loop region (H2 and H4) were identified in the present analysis of Morada Nova sheep. This information can aid in monitoring families within flocks so that maximal genetic diversity is maintained. The H5 haplotype was identified only in the Red variety and all three individuals identified were from the same farm (F), which could mean that they were closely related. As haplotype frequency was low, more studies are needed to test if this is specific to the Red variety. Pedrosa et al. (2007) observed the same haplotype in Bordaleira, Alcarreña eand Lacaune breeds. This family should be monitored and included in conservation programs to maximize genetic diversity of the flock. The ND5 region analyzed in this study was not efficient in the analysis of genetic diversity among the varieties of Morada Nova considered here. However, by analyzing a 460-bp fragment from D-loop region in conjunction with the Brazilian Somali hair sheep breed sequences published by Paiva et al. (2011) (Figure 3) Paiva et al (2011) (Figure 3) it was identified that the observed haplotypes in Morada Nova breed are present in another Brazilian hair sheep breeds. This result further supports the hypothesis of a common origin of Brazilian hair sheep (McManus et al., 2010). 
The results of this study will be used to validate the effective inclusion of germplasm of Black and White Morada Nova in the National Animal Germplasm Bank of the EMBRAPA Conservation Network as well as validate the use of mtDNA and microsattelite panel used in this study as a tool to aid in the management of Morada Nova breeding program.

\section{CONCLUSION}

Genetic differentiation among Red and White Morada Nova hair sheep was significant. Therefore, these varieties can be considered to be distinct genetic groups. The Black variety is a subgroup of the Red variety and should be included in Morada Nova conservation programs. The White variety shows a sub-structuring into two groups: one consisting of individuals from the State of Ceará and the other from Paraíba. The two haplotypes unique to the Morada Nova sheep found in the D-loop region can be used in monitoring families within flocks. The region of the ND5 gene sequenced in this study was not effective for determining diversity among varieties of Morada Nova sheep.

\section{ACKNOWLEDGMENTS}

The authors are extremely grateful to all of the private farms that kindly donated samples for this study. Research supported by Scientific Research grants from CNPq and Embrapa.

\section{Supplementary material}

\section{REFERENCES}

Amos W, Hoffman JI, Frodsham A, Zhang L, et al. (2007). Automated binning of microsatellite alleles: problems and solution. Mol. Ecol. 7: 10-14.

Bandelt HJ, Forster P and Rohl A (1999). Median-joining networks for inferring intraspecific phylogenies. Mol. Biol. Evol. 16: 37-48.

Berryere TG, Schmutz SM, Schimpf RJ, Cowan CM, et al. (2003). TYRP1 is associated with dun coat colour in Dexter cattle or how now brown cow? Anim. Genet. 34: 169-175.

Cinkulov M, Tapio M, Ozerov M, Kiselyova T, et al. (2008). Genetic differentiation between the Old and New types of Serbian Tsigai sheep. Genet. Sel. Evol. 40: 321-331.

Dalvit C, De MM, Zanetti E and Cassandro M (2009). Genetic variation and population structure of Italian native sheep breeds undergoing in situ conservation. J. Anim. Sci. 87: 3837-3844.

Egito AA, Mariante AS and Albuquerque MSM (2002). The Brazilian genetic resources conservation program. Arch. Zootec. 51: 39-52.

Excoffier L, Laval G and Schneider S (2006). Arlequin (Version 3.1): An Integrated Software Package for Population Genetics Data Analysis. University of Berne, Berne.

Fiore AM, Naik V, Spracklen DV, Steiner A, et al. (2012). Global air quality and climate. Chem. Soc. Rev. 41: 6663-6683.

Goudet J (2002). FSTAT, a Program to Estimate and Test Gene Diversities and Fixation Indices (Version 2.9.3). Available at [http://www.unil.ch/izea/softwares/fstat.htm]. Accessed June 2012.

Gratten J, Beraldi D, Lowder BV, McRae AF, et al. (2007). Compelling evidence that a single nucleotide substitution in TYRP1 is responsible for coat-colour polymorphism in a free-living population of Soay sheep. Proc. Biol. Sci. 274: 619-626.

Gutiérrez JP, Royo LJ, Alvarez I and Goyache F (2005). MolKin v2.0: a computer program for genetic analysis of populations using molecular coancestry information. J. Hered. 96: 718-721.

Hiendleder S, Mainz K, Plante Y and Lewalski H (1998). Analysis of mitochondrial DNA indicates that domestic sheep are derived from two different ancestral maternal sources: no evidence for contributions from Urial and Argali sheep. J. Hered. 89: 113-120. 
Huson DH and Bryant D (2006). Application of phylogenetic networks in evolutionary studies. Mol. Biol. Evol. 23: 254-267.

Librado P and Rozas J (2009). DnaSP v5: a software for comprehensive analysis of DNA polymorphism data. Bioinformatics 25: 1451-1452.

Mariante AS, Albuquerque MSM, Egito AA, McManus C, et al. (2009). Present status of the conservation of livestock genetic resources in Brazil. Livestock Sci. 120: 204-212.

McManus C, Paiva SR and Araújo RO (2010). Genetics and breeding of sheep in Brazil. Rev. Bras. Zootec. 39: 236-246.

McManus C, Cobuci J, Braccini Neto J and Paiva S (2011). Decision making in animal breeding programs and their consequences for animal production. Rev. Bras. Reprod. Anim. 35: 69-76.

Meadows JR, Li K, Kantanen J, Tapio M, et al. (2005). Mitochondrial sequence reveals high levels of gene flow between breeds of domestic sheep from Asia and Europe. J. Hered. 96: 494-501.

Miller SA, Dykes DD and Polesky HF (1988). A simple salting out procedure for extracting DNA from human nucleated cells. Nucleic Acids Res. 16: 1215.

Norris BJ and Whan VA (2008). A gene duplication affecting expression of the ovine ASIP gene is responsible for white and black sheep. Genome Res. 18: 1282-1293.

Paiva SR (2005). Caracterização da Diversidade Genética de Ovinos no Brasil com Quatro Técnicas Moleculares. Doctoral thesis. Universidade Federal de Viçosa, Viçosa.

Paiva SR, Silvério VC, Egito AA, McManus C, et al. (2005a). Genetic variability of the Brazilian hair sheep breeds. Pesq. Agropec. Bras. 40: 887-893.

Paiva SR, Silvério VC, Paiva DAF, McManus C, et al. (2005b). Origin of the main locally adapted sheep breeds of Brazil: a RFLP-PCR molecular analysis. Arch. Zootec. 54: 395-399.

Paiva SR, Faco O, Faria DA, Lacerda T, et al. (2011). Molecular and pedigree analysis applied to conservation of animal genetic resources: the case of Brazilian Somali hair sheep. Trop. Anim. Health Prod. 43: 1449-1457.

Pariset L, Mariotti M, Gargani M, Joost S, et al. (2011). Genetic diversity of sheep breeds from Albania, Greece, and Italy assessed by mitochondrial DNA and nuclear polymorphisms (SNPs). Sci. World J. 11: 1641-1659.

Peakall ROD and Smouse PE (2006). Genalex 6: genetic analysis in Excel. Population genetic software for teaching and research. Mol. Ecol. 6: 288-295.

Pedrosa S, Arranz JJ, Brito N, Molina A, et al. (2007). Mitochondrial diversity and the origin of Iberian sheep. Genet. Sel. Evol. 39: 91-103.

Pritchard JK, Stephens M and Donnelly P (2000). Inference of population structure using multilocus genotype data. Genetics 155: 945-959.

Qwabe SO, van Marle-Koster E and Visser C (2013). Genetic diversity and population structure of the endangered Namaqua Afrikaner sheep. Trop. Anim. Health Prod. 45: 511-516.

Raymond M and Rousset F (1995). GENEPOP (version 1.2): population genetics software for exact tests and ecumenicism. J. Hered. 86: 248-249.

Searle AG (1968). Comparative Genetics of Coat Colour in Mammals. Logos Press, London.

Tamura K, Peterson D, Peterson N, Stecher G, et al. (2011). MEGA5: molecular evolutionary genetics analysis using maximum likelihood, evolutionary distance, and maximum parsimony methods. Mol. Biol. Evol. 28: 2731-2739.

Tomiuk J, Guldbrandtsen B and Loeschcke V (1998). Population differentiation through mutation and drift - a comparison of genetic identity measures. Genetica 102-103: 545-558.

Tserenbataa T, Ramey RR, Ryder OA, Quinn TW, et al. (2004). A population genetic comparison of Argali sheep (Ovis ammon) in Mongolia using the ND5 gene of mitochondrial DNA; implications for conservation. Mol. Ecol. 13: 1333-1339.

Weir BS and Cockerham CC (1984). Estimating F-statistics for the analysis of population structure. Evolution 38: 13581370. 